\title{
Succinate Oxidation by Human Liver Mitochondria ${ }^{1}$
}

\author{
KEITH S. HENLEY ${ }^{2}$ AND EARL G. LAUGHREY \\ Department of Internal Medicine, Section of Gastroenterology, University of Michigan Medical School, \\ Ann Arbor, Michigan
}

Received May 10, 1965

\begin{abstract}
Factors controlling the rate of oxidation of succinate were studied in mitochondria isolated from twenty-seven specimens of normal human liver obtained at operation. These were compared with mitochondria prepared from the livers of anesthetized and unanesthetized rats. Previously reported lower rates of succinate oxidulion by human liver mitochondria were confirmed. This difference was no longer apparent when the succinic dehydrogenase activities of mitochondrial acetone powders were compared. The apparent $K_{m}$ of succinate for human liver mitochondrial succinoxidase is less than that of the anesthetized and unanesthetized rat. The concentration of oxalacetate is greater in human liver mitochondria compared with the anesthetized and unanesthetized rat. In both aerobic- and cyanide-inhibited mitochondria, the extent of the apparent succinate linked reduction of mitochondrial pyridine nucleotide was less in man than in the rat. In aerobic rat liver mitochondria, anesthesia lowers the extent of succinate-linked pyridine nucleotide reduction.
\end{abstract}

Previous work from this laboratory has shown that the rate of succinate oxidation by human liver mitochrondria is about one third of that found in the rat. This investigation was designed to compare some factors which determine succinate oxidation in man and rat, in an attempt to determine the the cause of this species difference and to study a possible effect of anesthesia on the oxidation of succinate.

\section{METHODS}

The collection of the liver biopsy specimens, the anaesthetics used, the preparation of the mitochondria, the polarographic determination of oxygen consumption, the assay of proteins and the preparation of mitochondrial extracts for fluorometric assay were performed as described in the earlier publication (1). Twenty-seven specimens of human liver were studied. Male, Sprague Dawley, albino rats were studied for

${ }^{1}$ This study was supported in part by grant AM-07361-2 from the U.S. Public Health Service.

2 Recipient of U. S. Public Health Service Research Career Development Award AM-K314,030 . comparison and as controls for the possible effects of anesthesia. Where indicated in the text, these rats had been anesthetized with ether for 1 hour prior to sacrifice.

For the measurement of succinic dehydrogenase activity $(2)^{3}$ mitochondrial powders were prepared by precipitation and homogenization in a minimum of twenty-five volumes of acetone at $-10^{\circ} \mathrm{C}$. The precipitate was collected in a Buchner funnel and rehomogenized in $0.3 M$ phosphate buffer, $p \mathrm{H}$ 7.6. Enzyme activity was measured polarographically by the method of Singer and Kearney (3), phenazine methosulfate was used as the electron acceptor. Maximal enzyme activities were calculated from a series of measurements according to Lineweaver and Burk (4).

${ }^{3}$ In agreement with the nomenclature introduced by Keilin and Hartree (2), the term "succinoxidase" denotes the enzyme system capable of oxidizing succinate in the presence of molecular oxygen. The term "succinic dehydrogenase" denotes the enzyme system capable of oxidizing succinate in the presence of molecular oxygen with an artificial electron acceptor such as phenazine methosulfate being interposed between the enzyme and molecular oxygen, thus bypassing part of the electron transport chain. 


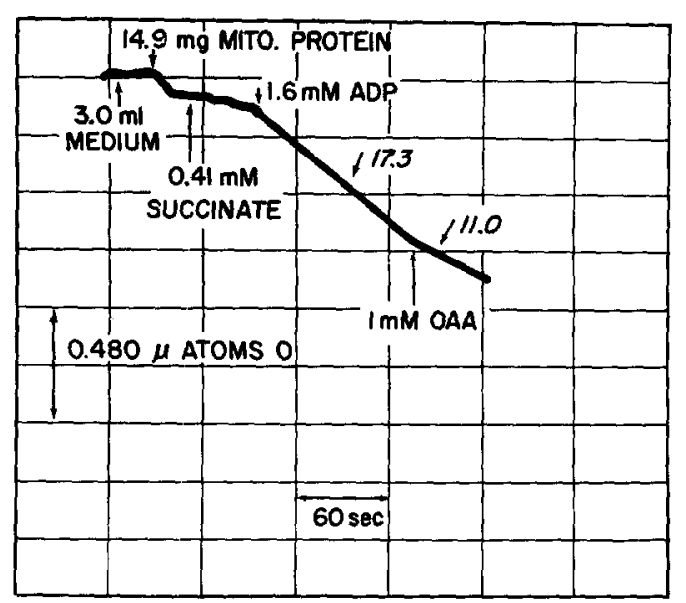

Frg. 1. Inhibition of oxidation of succinate by oxalacetate. Human liver mitochondria (specimen 1). Medium as in Ref. (1). Italicized figures represent rates of oxygen consumption ( $\mu$ atoms/hour).

For the determination of the maximal velocities of succinate oxidation, of the apparent $K_{m}$ for succinate and the apparent $K_{i}$ for oxalacetate, mitochondria were incubated with isotonic medium (1), $\mathrm{pH} 7.2$, sodium succinate in a final concentration of between 1.64 and $0.205 \mathrm{mM}$, followed by $1.6 \mathrm{~m} M$ ADP.4 When a steady state of oxygen consumption had been established, the medium was made $1 \mathrm{~m} M$ in freshly prepared oxalacetate solution and the new and lower rate of oxygen consumption recorded (Fig. 1). Plots of the reciprocal of succinate concentration against the reciprocal of the rate of oxygen uptake gave the expected pattern of competitive inhibition of succinate by oxalacetate (5) (Fig. 2). The $K_{m}$ and $K_{i}$ values were calculated from the regression lines.

The order of addition of mitochondria, substrates and phosphate acceptor has been selected to show that each specimen showed evidence of respiratory control, i.e., an increase in the rate of respiration on the addition of $\mathrm{ADP}$ to the medium containing succinate. This precluded measurement of the rate of endogenous respiration with ADP in the absence of succinate.

4 Abbreviations used: ADP, adenosine diphosphate; A.TP, adenosine triphosphate; EDTA, ethylenediaminetetracetate (disodium salt); LDH, lactic acid dehydrogenase; $\mathrm{MDH}$, malic acid dehydrogenase; NAD, nicotinamide adenine dinucleotide; NADH, reduced nicotinamide adenine dinucleotide; OAA, oxalacetate; PCA, perchloric acid; PN, pyridine nucleotide; TRAP, triethanolamine hydrochloride.
For the estimation of succinate induced reduction of mitochondrial pyridine nucleotides, the Eppendorf fluorometer with amplifier and recorder described by Estabrook (6) was used. Mitochondria containing $2-10 \mathrm{mg}$ of protein were added to $2.85 \mathrm{ml}$ of $0.25 M$ sucrose, $10 \mathrm{~m} M$ TRAP buffer pH 7.2 , and $1 \mathrm{~m} M$ EDTA. When the medium was made $8 \mathrm{~m} M$ in acetoacetate (prepared as described by Krebs and Eggleston ( 7 ), the reduced pyridine nucleotides were gradually oxidized until a steady state was reached. Upon the addition of succinate in $4.1 \mathrm{~m} M$ final concentration, an increase in fluorescence representing pyridine nucleotide reduction was recorded. For the measurement of pyridine nucleotide reduction in terminally inhibited mitochondria, $1.5 \mathrm{~m} M$ potassium cyanide was present in the medium before the addition of the mitochondria. In view of the need for an added source of energy under these conditions (8), ATP (4.1 $\mathrm{m} M$ final concentration) was added after the succinate (Fig. 3). Each incubation mixture was calibrated by the addition of a small volume of $\mathrm{NADH}$ of known optical density to a colloidal solution of equivalent background fluorescence (e.g., dilute milk).

For the estimation of oxalacetate, mitochondria were added to four volumes of chilled $6 \%$ PCA, and the mixture thoroughly homogenized in the cold. The extract was then neutralized to methyl orange with $5 M$ potassium carbonate. Since such a neutralized PCA extract contains malic dehydrogenase (9), oxalacetate was converted to pyruvate by heating for 30 minutes at $70^{\circ} \mathrm{C}$. The heated extract was recentrifuged and made to a known volume with $0.2 M$ TRAP buffer, $\mathrm{pH}$ 7.6. The concentration of pyruvate was then determined fluorimetrically with lactic dehydrogenase and NADH.

\section{RESULTS}

Oxalacetate was converted quantitatively to pyruvate in 30 minutes at $70^{\circ} \mathrm{C}$ (Table I). As measured by us, the apparent concentration of oxalacetate represents the sum of the concentrations of oxalacetate and pyruvate. There are, however, a number of reasons which suggest that the original concentration of the latter is low or negligible.

1. Pyruvate is considered to be a representative of the extramitochondrial portion of the cell $(9)$.

2. While, in both human and rat liver mitochondria, between 30 and $45 \%$ of the apparent concentration of oxalacetate was already present as pyruvate when the heating step was omitted, it appeared likely that 


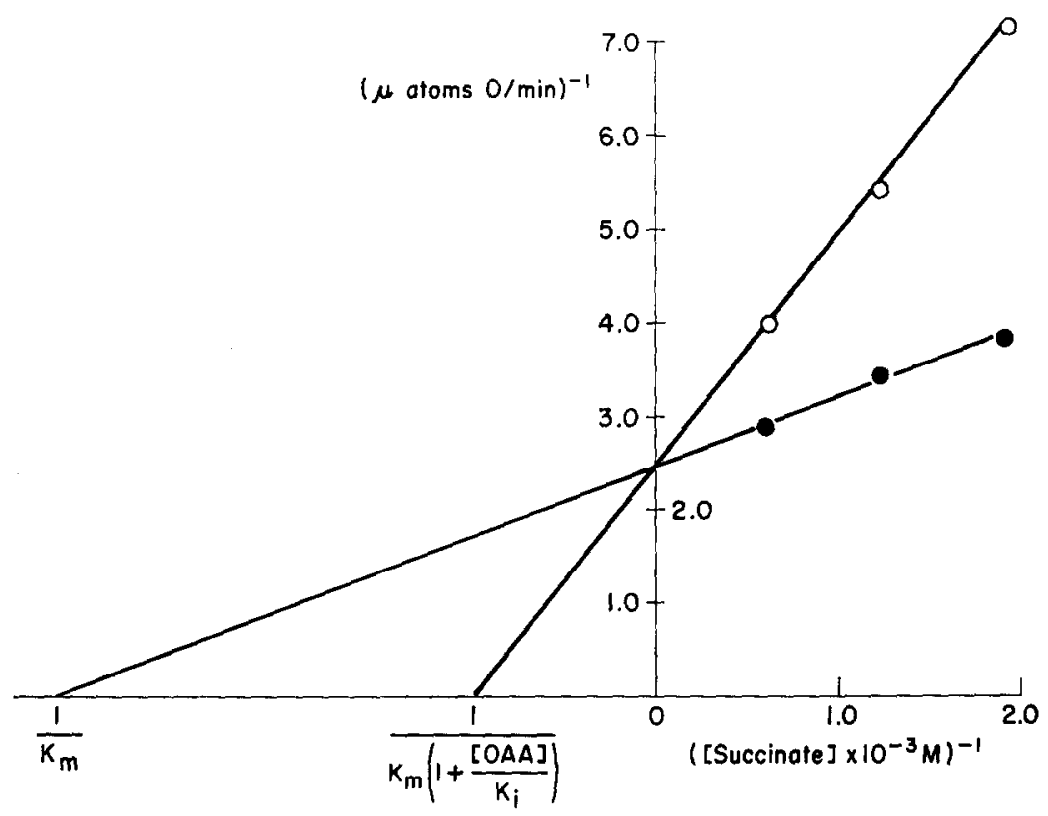

FIG. 2. Competitive inhibition of succinate oxidation by oxalacetate. Human liver mitochondria (specimen 2); $6.56 \mathrm{mg}$ of protein, final volume $3.0 \mathrm{ml}$. (Opresent; (- ) OAA absent.

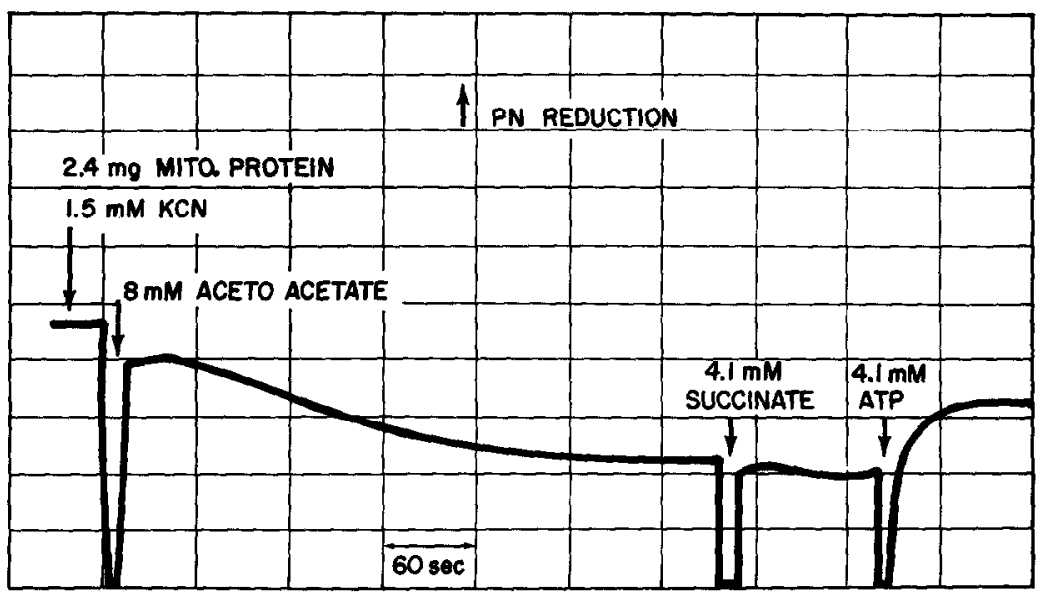

Fic. 3. Succinate linked pyridine nucleotide reduction. Human liver mitochondria (specimen 3). For experimental details see text.

this pyruvate had been formed by decarboxylation of mitochondrial oxalacetate. This was supported by experiments in which mitochondria were incubated with added oxalacetate in ice, for a period of one hour. Under these conditions pyruvate was formed at a rate of $0.30-0.40 \mathrm{~m} \mu$ mole per milligram protein per minute. While this is presumably a maximal rate it accounts adequately for the very small quantities of pyruvate formed during the isolation of the mitochondria.

3. Other possible precursors of pyruvate such as phosphoenol pyruvate or malate were not converted to pyruvate by the pro- 
cedure of extraction with acid, neutralization and heating and in the absence of tissue components.

The results of the experiments are summarized in Table $\mathrm{II}$.

\section{DISCUSSION}

The previously reported differences in the rates of succinate oxidation between human and rat liver were confirmed by the calcu-

TABLF I

\begin{tabular}{cccc} 
Conversion & $\begin{array}{c}\text { OF } \begin{array}{c}\text { OXalacetate } \\
\text { AT } 70^{\circ} \mathrm{C}^{a}\end{array} \\
\begin{array}{c}\text { Period of } \\
\text { heating (min) }\end{array}\end{array}$ & \multicolumn{4}{c}{$\begin{array}{c}\Delta \mathrm{OD} \\
\text { After MDH }\end{array}$} & $\begin{array}{c}\text { After LDH } \\
\text { plus MDH }\end{array}$ & $\begin{array}{c}\text { Difference } \\
\text { due to LDH }\end{array}$ \\
\hline 0 & 0.736 & 0.740 & 0.004 \\
10 & $\mathbf{0 . 1 9 7}$ & 0.741 & 0.544 \\
20 & 0.026 & 0.738 & 0.712 \\
30 & 0.010 & 0.738 & 0.728 \\
40 & 0.011 & 0.744 & 0.733 \\
\hline
\end{tabular}

a A solution of oxalacetate (approximately $0.40 \mu \mathrm{mole} / \mathrm{ml}$ ) was heated at $70^{\circ} \mathrm{C}$ for the periods of time stated. One-ml aliquots were then assayed in $0.067 M$ phosphate buffer ( $\mathrm{pH} 7.5$ ) with NADH and enzymes as indicated at $340 \mathrm{~m} \mu$. Final volume, $3.0 \mathrm{ml}$. lated maximal velocities shown in Table II. This confirms that the substrate concentrations used in the previously reported experiments were near-optimal, and well in excess of the apparent $K_{m}$ for both human and rat liver mitochondria. Indeed the apparent $K_{m}$ of human liver mitochondria was significantly lower $(P<0.01)$ compared with the anesthetized and unanesthetized rat. There was no significant difference in the apparent $K_{i}$ 's between the three groups of specimens. The $K_{i}$ 's were, however, much higher than those previously reported by Pardee and Potter (5). Their classical studies were carried out on whole tissue homogenates whereas in our experiments isolated mitochondria were used. There were numerous other differences in experimental conditions.

When mitochondrial structure was destroyed by treatment with ice-cold acetone in a Waring Blendor and the activity of succinic dehydrogenase measured, the species difference in the rate of oxidation of succinate is removed, and possibly reversed, although the activity in the human specimens showed marked and unexplained variability. It seems probable that differences in

TABLE II

Factohs Affecting Succinate Oxidation by Liver Mrtochondria from Man and Rata

\begin{tabular}{|c|c|c|c|}
\hline & Man & Anesthetized rat & Unanesthetized rat \\
\hline $\begin{array}{l}\text { Maximal velocity ( } \mu \text { atoms } 0 / \mathrm{mg} \\
\text { prot./hour) }\end{array}$ & $2.41 \pm 0.41$ & $\begin{array}{c}7.30 \pm 0.55 \\
(10)\end{array}$ & $\begin{array}{c}7.07 \pm 1.09 \\
(6)\end{array}$ \\
\hline$K_{m}\left(\times 10^{-3} M\right)$ & $0.18 \pm 0.04$ & $\begin{array}{c}0.64 \pm 0.08 \\
(10)\end{array}$ & $\begin{array}{c}1.03 \pm 0.19 \\
(11)\end{array}$ \\
\hline$K_{i}\left(\times 10^{-3} M\right)$ & $0.42 \pm 0.06$ & $\begin{array}{c}0.26 \pm 0.09 \\
(10)\end{array}$ & $\begin{array}{c}0.38 \pm 0.12 \\
(7)\end{array}$ \\
\hline $\begin{array}{l}\text { Succinic dehydrogenase ( } \mu \text { atoms } 0 / \mathrm{mg} \\
\text { prot./hour) }\end{array}$ & $\begin{array}{l}\text { Individual } \\
\text { determinations } \\
29.3,48.2,304.8 \\
530.8,16.5,58.9\end{array}$ & $\begin{array}{c}12.00 \pm 1.84 \\
(10)\end{array}$ & $\begin{array}{c}15.66 \pm 1.66 \\
(11)\end{array}$ \\
\hline $\begin{array}{l}\text { Apparent PN reduction (aerobic) } \\
\text { (m } \mu \text { moles } / \text { mg protein) }\end{array}$ & $1.34 \pm 0.33$ & $\begin{array}{c}2.71 \pm 0.27 \\
(10)\end{array}$ & $\begin{array}{c}4.46 \pm 0.46 \\
\text { (11) }\end{array}$ \\
\hline $\begin{array}{l}\text { Apparent } \text { PN reduction (cyanide } \\
\text { inhibited) (m } \mu \text { moles } / \text { mg protein) }\end{array}$ & $\begin{array}{c}2.19 \pm 0.33 \\
(6)\end{array}$ & $\begin{array}{c}5.62 \pm 0.52 \\
(10)\end{array}$ & $\begin{array}{c}6.40 \pm 0.66 \\
(15)\end{array}$ \\
\hline $\begin{array}{l}\text { Concentration of OAA ( } \mathrm{m} \mu \text { moles } / \mathrm{mg} \\
\text { protein) }\end{array}$ & $1.00 \pm 0.27$ & $\begin{array}{c}0.07 \pm 0.01 \\
(11)\end{array}$ & $\begin{array}{c}0.18 \pm 0.04 \\
(12)\end{array}$ \\
\hline
\end{tabular}

a All determinations carried out at $25^{\circ} \mathrm{C}$. Except where otherwise stated, figures represent means and standard error of the mean. Figures in parentheses represent the number of observations. 
the structure or composition of the acetone soluble portion of the mitochondrial membrane are responsible for the observed species differences.

To explore an alternative pathway of succinate oxidation, succinate linked reduction of pyridine nucleotides was measured. In both the aerobic and cyanide inhibited states, succinate linked pyridine nucleotide reduction was less in human liver mitochondria compared with the anesthetized and unanesthetized rat $(p<0.001)$. The recorded differences in the apparent concentrations of reduced pyridine nucleotides do not, however, represent a rate but a difference in two steady states of pyridine nucleotide reduction. Upon the addition of acetoacetate, an equilibrium

\section{$\mathrm{NADH} \times$ Acetoacetate $\overline{\text { NAD } \times \beta \text {-Hydroxybutyrate }}$}

is obtained by means of the $\beta$-hydroxybutyrate dehydrogenase reaction. The addition of succinate establishes a new steady state because of the increase in NADH resulting from succinate linked reduction of pyridine nucleotides (10). These experiments were carried out in mitochondrial suspensions rather than extracts. The pyridine nucleotides were, therefore, presumably bound to protein and exhibited fluorescence enhancement (11). Such fluorescence enhancement has been shown by Estabrook to vary from a factor of four to twelve in rat liver mitochondria under different metabolic conditions (6). The difference in pyridine nucleotide reduction between the two steady states is therefore an indirect representation of the actual quantities of pyridine nucleotides reduced. Since these experiments were carried out under identical conditions, the data can be compared.

Differences in "reversed oxidation" of succinate are not necessarily relevant to the extent of "forward" oxidation of succinate. The documentation of any possible relationship between "forward" and "reverse" oxidation would require the measurement of succinate disappearance. Currently available methods do not lend themselves readily to the determination of small changes of succinate concentration.
Attempts were made to measure the rate of acetoacetate disappearance in the presence of succinate using the procedure deseribed by Klingenberg (8). This was feasible in both the anesthetized and unanesthetized rat, but, for unknown reasons, not in the three specimens of human liver mitochondria where this was attempted.

The concentration of oxalacetate, an inhibitor of succinate oxidation (5), was significantly higher in human liver mitochondria compared with the anesthetized and unanesthetized rat $(p<0.01)$. This does not explain the observed species difference in the maximal rates of succinate oxidation because, as is the case for any competitive inhibitor, again exemplified in Fig. 2, the maximal velocity is independent of the presence of the inhibitor or its concentration. For oxalacetate to be an inhibitor under conditions of less than maximal rates of succinate oxidation in vivo, would require that oxalacetate, tentatively located outside the cristae half-membrane by Klingenberg (12) would be accessible to the respiratory chain dehydrogenases located on the cristae halfmembrane. Furthermore, and particularly for low concentrations of succinate, the lower $K_{m}$ of human liver mitochondria for succinate might reverse a possible inhibitory effect of oxalacetate.

Anesthetized rats were studied as an additional control to determine whether anesthesia would modify the factors responsible for the different rates of succinate oxidation in man and rat. The effects of anesthesia were clearly less evident than the species differences. Anesthesia may have lowered the concentration of mitochondrial oxalacetate, but this was of doubtful significance $(0.05>p>0.02)$. A more striking differcrence was in the acrobic reduction of mitochondrial pyridine nucleotides. This was lowered in the anesthetized compared with the normal rate $(p<0.01)$, and is an aspect of the metabolic effects of anesthetics which deserves further study.

\section{ACKNOWLEDGMENT}

We wish to thank I)r. Charles G. Child, III and the staff of the Department of Surgery, University of Michigan, for the biopsy specimens. 


\section{REFERENCES}

1. Henley, K. S., Napier, E. A., Jr., Kreyden, R. W., Corssen, G. C., and Berendsohn, S., J. Lab. Clin. Med, 64, 306 (1964).

2. Kkeilin, 1)., and Hartree, E. F. Proc. Soc. (Londan) Ser. B 129, 277 (1940).

3. Singer, T. P., and Kearney, E. B., in "Methods of Biochemical Analysis" (D. Glick, ed.), Vol. 4, p. 307. Wiley (Interscience), New York (1957).

4. Iineweaver, H., and B ७ Rk, I)., J. Am. Chem. Soc. 56, 658 (1934).

5. Pardee, A, B., And Potter, V. R., J. Biol. Chem. 176, 1085 (1948).
6. Fstabrook, R. W., Anal. Biochem. 4, 231 (1962).

7. Krebs, H. A., and EgGleston, L. V., Biochem. J. 39, 408 (1945).

8. Klingenberg, M., and von Haefen, H., Biochem. Z. 337, 120 (1963).

9. Hohonst, H. J., in "Funktionelle und Morphologische Organisation der Zelle," p. 194. Springer Verlag, Berlin (1963).

10. Chance, B., and Hollunger, G., J. Biol. Chem. 236, 1534 (1961).

11. Chance, B., and Baltscheffesky, H., $J$. Biol. Chem. 233, 736 (1958).

12. Kungenberg, M., in "Energy Linked Functions of Mitochondria" (B. Chance, ed.), p. 121, Academic Press, New York (1963). 